\title{
An Approach towards Pulse Data Transmission Using Modified Negative Luo Converter (MNLC) for Telecoms
}

\author{
V. Chamundeeswari ${ }^{1}$, Dr. R. Seyezhai ${ }^{2}$ \\ ${ }^{1}$ Department of EEE, St. Joseph's College of Engineering, Chennai, India \\ ${ }^{2}$ Department of EEE, SSN College of Engineering, Chennai, India \\ Email: chamuvins@gmail.com,seyezhair@ssn.edu.in
}

Received 4 April 2016; accepted 1 May 2016; published 29 July 2016

Copyright (C) 2016 by authors and Scientific Research Publishing Inc.

This work is licensed under the Creative Commons Attribution International License (CC BY).

http://creativecommons.org/licenses/by/4.0/

(c) $\underset{\mathrm{EY}}{\mathrm{ir}}$ Open Access

\begin{abstract}
Telecom sectors generally operate at negative voltages to reduce the effect of corrosion caused in the metallic wire due to electrochemical reaction while communicating signals. To feed those lines and to have an effective digital data transmission, a power electronic converter referred as Modified Negative Luo Converter (MNLC) is proposed in this paper. MNLC is a high gain converter in which the output voltage increases in geometric progression. This paper portrays a novel concept of a $50 \mathrm{~Hz}$ pulse data transmission through RLCG (Resistance-inductance-capacitance with a shunt conductance) transmission line using MNLC. Signal frequency of $50 \mathrm{~Hz}$ to be transmitted is anded with a high frequency pulse that charges and discharges MNLC and produces the boosted negative output voltage. The boosted output is again transmitted through the RLCG transmission line from which $50 \mathrm{~Hz}$ data pulse is retrieved at the output of the transmission line by comparing with a comparator signal. This sort of MNLC aided data transmission not only introduces less loss in its transmitted data but also overcomes various health hazards of conventional radio frequency (RF) communication. This technique also proves that any data bit stream can be transmitted and retrieved using the proposed high gain DC-DC converter. The simulation model of the proposed system is implemented in MATLAB for various switching frequencies with its prototype of the converter developed and the results are verified.
\end{abstract}

\section{Keywords}

Pulse Data Transmission, MNLC, RLCG Line, Switching Frequency, High Gain Converter

\section{Introduction}

The usage of $-48 \mathrm{~V}$ DC in the telecom sectors exists in current scenario and the telecom stations always require

How to cite this paper: Chamundeeswari, V. and Seyezhai, Dr.R. (2016) An Approach towards Pulse Data Transmission using Modified Negative Luo Converter (MNLC) for Telecoms. Circuits and Systems, 7, 2712-2728. 
voltage in the range between $-45 \mathrm{~V}$ and $-55 \mathrm{~V}$ for safe operation. This negative voltage also helps in preventing corrosion of the metallic copper when operated under wet conditions. The sulphation of the battery which leads to failure is also eliminated by the usage of negative signal, since the build of lead sulphate only leads to battery failure. When the metallic leads used for communication are at negative potential with respect to ground, the metal ions go form the ground to the wire instead of the situation where positive voltage would cause quick corrosion. Thus the electrochemical reaction causing corrosion is highly avoided by maintaining the negative potential feeding the telecom lines. In this, the negative output voltage is produced using MNLC and it also focuses on effective pulse data transmission which plays a vital role in telecoms.

Radio frequency waves possess the longest wavelength in the electromagnetic spectrum. They also have a uniform frequency and amplitude at all time instants [1]. So, data can be transmitted effectively by placing at the RF wave using frequency and amplitude modulation techniques. The same data can be retrieved at the receiver by using antennas and the tuner [2]. Though the data can be retrieved in an effective way, RF cannot transmit a lot of data simultaneously and also causes lots of health disorders. To overcome this, data transmission is achieved effectively in this paper using MNLC in a safer way than RF communication [3].

MNLC is a modified superlift converter in which the output voltage increases in geometric progression with six times the gain compared to the conventional NOSLC whose gain value is three. Here the data pulse transmission concept is implemented with the switching pulse of MNLC. The pulse activates the process of on and off of the MNLC circuit that produces a very high output voltage. Ultimately data pulse retrieval is obtained only from the boosted voltage.

Section 2 deals with the explanation of overview of the proposed system, and Section 3 portrays the operation of MNLC with its modes and analysis followed by its simulation results. The modeling of RLCG transmission line has been dealt in Section 4. Section 5 explains the concept of interface of MNLC with the transmission line followed by the simulation results of data transmission for various switching frequencies. Section 6 depicts the hardware model of MNLC implemented in open loop followed by conclusion in Section 7.

\section{Proposed System}

The block diagram of the proposed system is given in Figure 1. The data pulse transmission concept is explained here. A $50 \mathrm{~Hz}$ data pulse is transmitted through MNLC interfaced with RLCG transmission line. This is effectively carried out by adding the transmitting pulse with the required switching frequency of $25 \mathrm{kHz}$. The anded high frequency pulse produced as a result, acts as an energizing pulse of the switch. This switches on and off the MNLC and produces the boosted negative output voltage. The boosted output is transmitted through the RLCG transmission line from which $50 \mathrm{~Hz}$ pulse is retrieved by comparing with the comparator signal.

The RLCG parameters have been modeled for coverage of 1000 meters and discussed in the forth coming section. RLCG is a combination of RLC circuit with a shunt conductance ' $G$ '. The transmitted voltage through the RLCG line is the boosted output from MNLC. The enhanced output from MNLC transmits the required data effectively.

\section{MNLC and Its Operational Modes}

\subsection{Operation of MNLC}

Figure 2 shows the elementary circuit of MNLC [4]. It consists of DC supply voltage $V_{i n}$, capacitors $C_{1}$ and $C_{2}$, inductor $L_{1}$ and $L_{2}$ switch $\mathrm{S}$, diodes $D_{1}, D_{2}$ and $D_{3}$ and the load resistance R. The working principle is explained with the switch "S" on and off as two modes of operation as shown in Figure 3, Figure 4.

During mode-I, the switch $\mathrm{S}$ is turned $\mathrm{ON}$ between the period 0 and $\Delta T$ as shown in Figure 3 . When the switch is closed, the source voltage causes the current to flow through the inductor $L_{1}$ and capacitor $C_{1}$. Since capacitor $C_{1}$ and has zero impedance to current, the capacitor $C_{1}$ charges faster than inductor thus forward biasing the diode $D_{1}$. Thus charge gets stored in inductor $L_{1}, L_{2}$ and Capacitor $C_{1}$, also during this period, the load current is maintained constant by the discharging capacitor $C_{2}$. Thus the energy stored in the capacitor $C_{2}$ during the previous cycle is transferred to the load.

During mode-2, the switch $\mathrm{S}$ is turned off between the period $\Delta T$ and $T$ as shown in Figure 4. In this mode, when the switch is open, the energy that is stored in the inductor $L_{1}, L_{2}$ and the capacitor $C_{1}$ discharges across the nodal points of the capacitor $C_{2}$ thus boosting the output voltage. The load current is supplied by the inductor. 


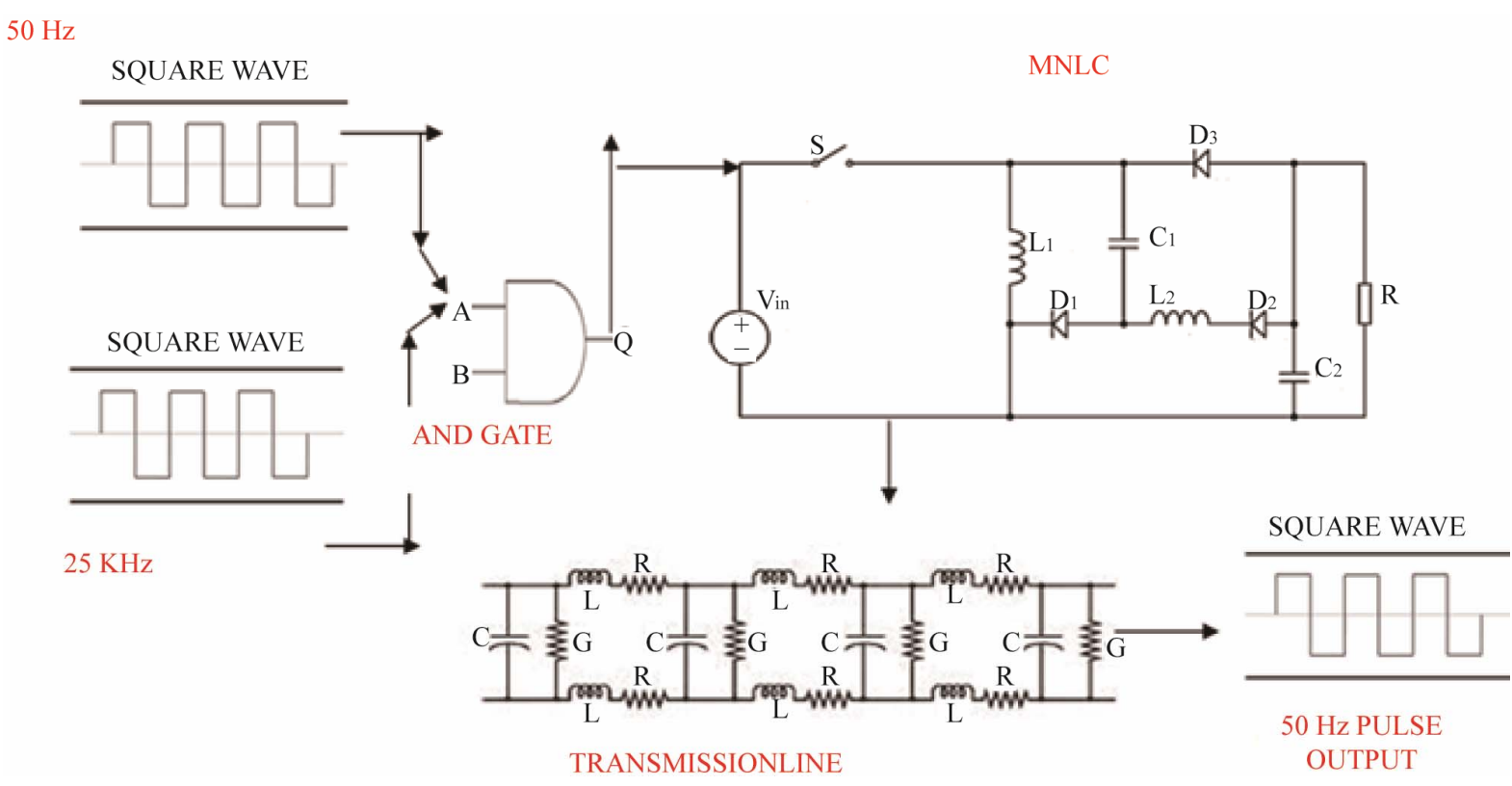

Figure 1. Block diagram of the proposed system.

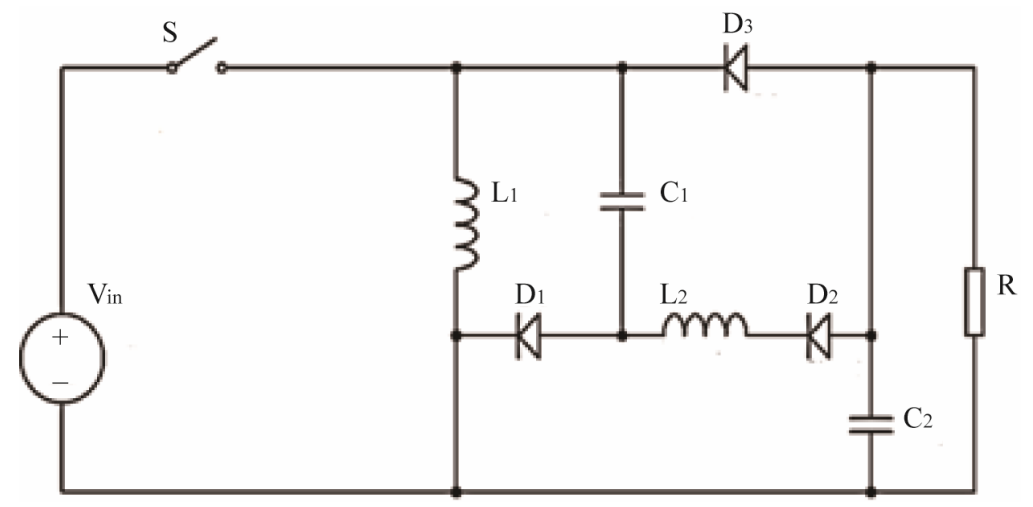

Figure 2. Circuit diagram of MNLC.
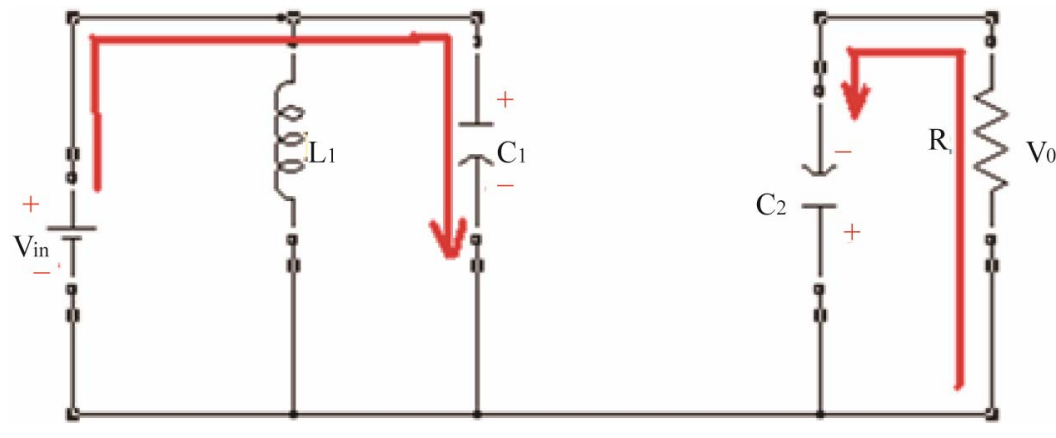

Figure 3. Mode 1 diagram of MNLC.

\subsection{Analysis of MNLC}

The equations governing mode-I are as follows,

$$
V_{i n}=\frac{L_{1} \mathrm{~d} i_{i}}{\mathrm{~d} t}
$$




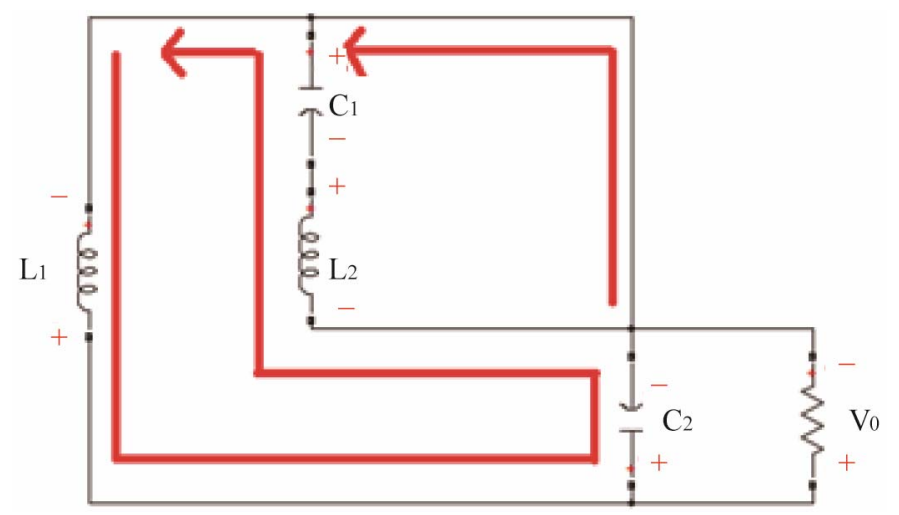

Figure 4. Mode 2 diagram of MNLC.

$V_{\text {in }}$ can also be represented as,

$$
V_{C_{1}}=V_{i n}
$$

Here $V_{C_{1}}$ is the voltage across the capacitor $C_{1}$.

The current through the inductor $L_{1}$ is given by,

$$
I_{L_{1}}=\frac{V_{\text {in }} \mathrm{d} t}{L_{1}}=\frac{V_{\text {in }} k T}{L_{1}}
$$

$k$ is the duty ratio and $T$ is the on-period cycle.

The voltage across the capacitor $C_{2}$ is the load or the output voltage $V_{0}$ and it is given as,

$$
V_{C_{2}}=V_{0}
$$

The current through the capacitor $C_{2}$ during on is given by,

$$
I_{C_{2 o n}}=I_{0}=\frac{C \mathrm{~d} v_{0}}{\mathrm{~d} t}
$$

From Mode II:

During mode-II, the current through the inductor $L_{1}$ is given by,

$$
I_{L_{1}}=\frac{V_{0}-V_{i n}}{L_{1}} \mathrm{~d} t=\frac{V_{0}-V_{i n}}{L_{1}}(1-k) T
$$

Here $V_{0}$ is the output voltage and $(1-k) T$ is the off-period cycle.

The current through the inductor $L_{2}$ is given by,

$$
I_{L_{2}}=\frac{V_{0}-V_{i n}}{L_{2}} \mathrm{~d} t=\frac{V_{0}-V_{i n}}{L_{2}}(1-k) T
$$

Equating (3) \& (6),

$$
\frac{V_{i n} k T}{L_{1}}=\frac{V_{0}-V_{i n}}{L_{1}}(1-k) T
$$

From the above, the gain equation is obtained as,

$$
\frac{V_{0}}{V_{\text {in }}}=\frac{2}{1-k}
$$

The output voltage is given by,

$$
V_{0}=\frac{2 V_{i n}}{1-k}
$$


The values of $L_{1}, L_{2}, C_{1}$ and $C_{2}$ are derived from the following analysis equations of MNLC.

Variation ratio of the output voltage is given by,

$$
\varepsilon_{1}=\frac{1-k}{2 f R C_{1}}
$$

By substituting the values for frequency, resistance and $k$ as $50 \mathrm{kHz}, 100 \Omega$ and $67 \%$, the value of $C_{1}$ is found as $30 \mu \mathrm{F}$ and $C_{2}$ is also found using the equation for $\varepsilon_{2}$ and the value is $10 \mu \mathrm{F}$.

$L_{1}, L_{2}$ are estimated using the following relation and found to be $0.01 \mathrm{mH}$.

$$
I_{L_{1}}=\frac{V_{\text {in }} \mathrm{d} t}{L_{1}}=\frac{V_{\text {in }} k T}{L_{1}}
$$

Using the above design equations, the component parameters are computed as shown in Table 1 [5].

\subsection{Simulation Results}

The MNLC is simulated using the above design values and the results are depicted in the following figures.

MNLC is simulated for an input voltage of $20 \mathrm{~V}$ as shown in Figure 5 . The output voltage obtained is $-121 \mathrm{~V}$ which is shown in Figure 6. It also depicts that the output voltage is six times the input and so the gain value is six which is drastically high compared to the conventional NOSLC. The charging elements include $C_{1}$, the input side capacitor and the load capacitor $C_{2}$. The voltage across the capacitor $C_{1}$ is shown as $19 \mathrm{~V}$ in Figure 7 . The output current is shown as -1.25 amps in Figure 8. Figure 9 represents the voltage across the diode $D_{3}$ as $140 \mathrm{~V}$ and Figure 10 shows the voltage across the diode $D_{2}$ as $130 \mathrm{~V}$.

\section{Modelling of Transmission Line}

The modeling of transmission cable through which the negative voltage is transmitted to influence effective data transmission is explained in this section. The transmission line comprises of a RLCG circuit and it has been modelled for distance coverage of 1000 meters.

Table 1. Design values of MNLC.

\begin{tabular}{ccc}
\hline SL. No & Parameter & Values \\
\hline 1. & $V_{\text {in }}$ (Input voltage) & $20 \mathrm{~V}$ \\
2. & $f_{s}$ (switching frequency) & $50 \mathrm{kHz}$ \\
3. & $k$ (Duty ratio) & 0.67 \\
4. & $R$ (Resistive load) & $100 \Omega$ \\
5. & Expected $V_{0}$ (Output voltage) & $-121.1 \mathrm{~V}$ \\
6. & $L_{1}, L_{2}$ (Inductors) & $0.01 \mathrm{mH}$ \\
\hline
\end{tabular}

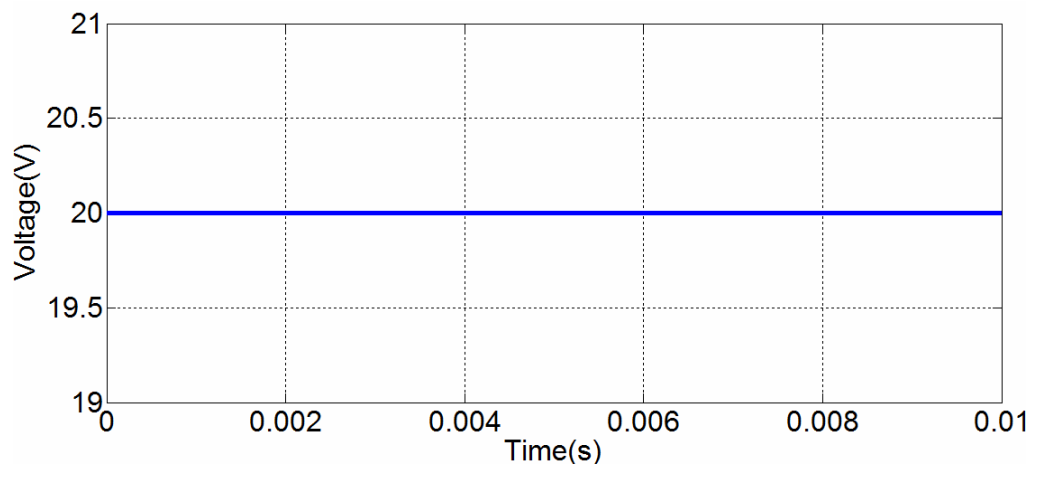

Figure 5. Input voltage of MNLC $20 \mathrm{~V}$. 


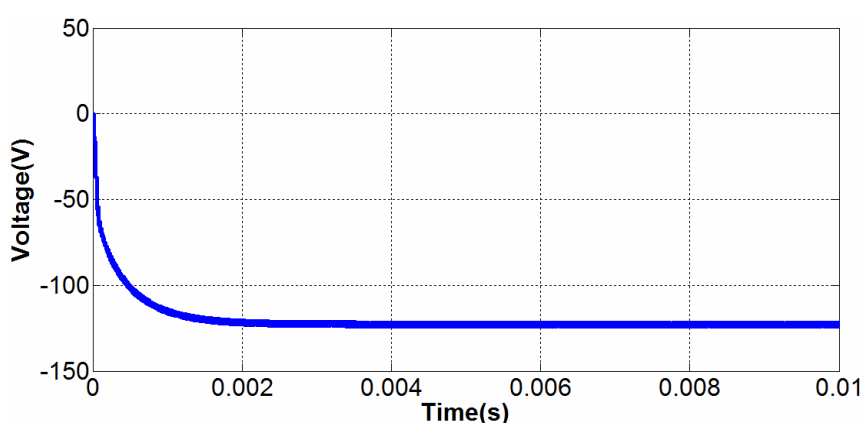

Figure 6. Output voltage of MNLC $-121 \mathrm{~V}$.

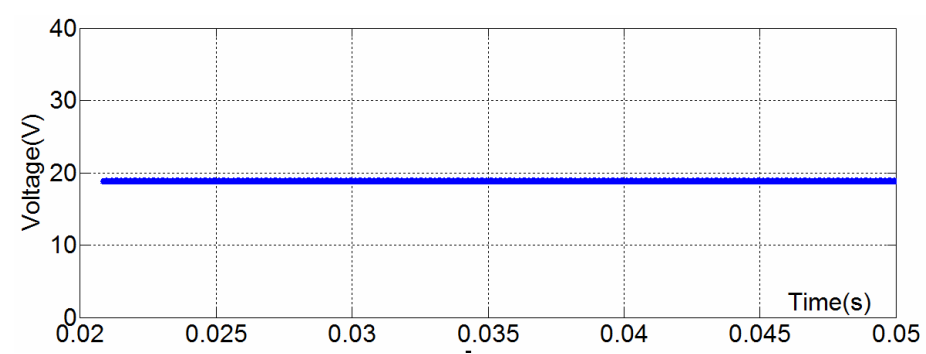

Figure 7. Voltage across the capacitor $C_{1} 19 \mathrm{~V}$.

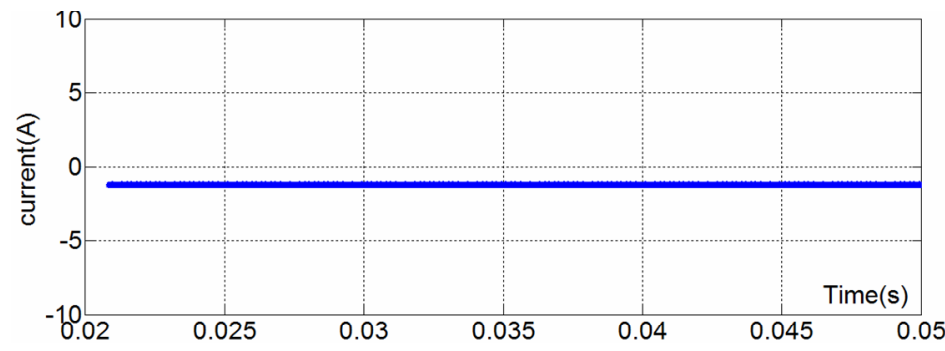

Figure 8. Output current of MNLC -1.25 A.

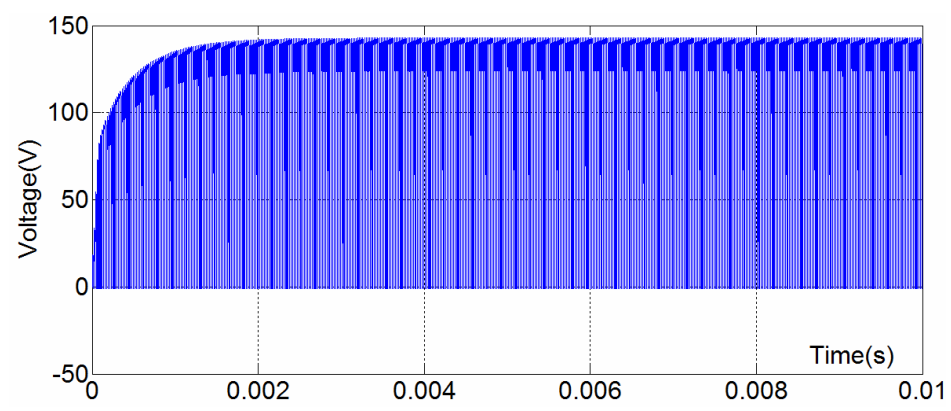

Figure 9. Voltage across the diode $D_{3} 140 \mathrm{~V}$.

\section{Analysis of RLCG Section}

The transmission line has four parameters namely resistance $(R)$, inductance $(L)$, capacitance $(C)$ and a shunt conductance which is named as RLCG circuit. The capacity of the power transmission is maintained only by the series inductance of the RLCG circuit. The shunt capacitance causes a charging current to flow in the line and plays a significant role in medium and long lines. These parameters are uniformly distributed throughout but can be made as a lumped circuit for analysis.

Having all this assumption, the equations for series resistance, inductance and capacitance of RLCG circuit is given in the following analysis. 


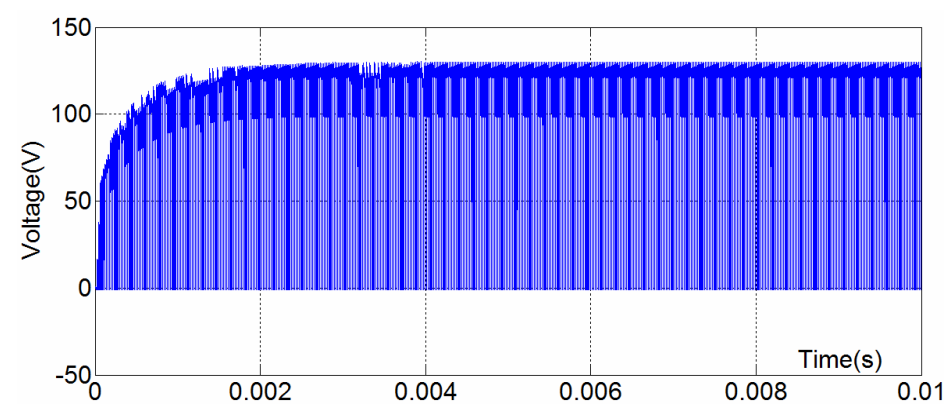

Figure 10. Voltage across the diode $D_{2} 130 \mathrm{~V}$.

\section{Resistance in RLCG circuit $(R)$}

The dc resistance is given by:

$$
R=\frac{\rho l}{a}
$$

$\rho=$ resistivity of conductor $-\Omega \cdot \mathrm{m}$.

$l=$ length in $\mathrm{m}$.

$a=$ cross-sectional area $-\mathrm{m}^{2}$.

The distribution of current is uniform only for dc and becomes non-uniform when it comes for ac. With the increase of frequency, the non-uniformity also increases. The resistance of metals increases with increase in temperature. It increases linearly and the resistance at temperature " $t$ " is given by,

$$
R_{t}=R_{0}(1+\alpha \Delta t)
$$

$R_{\mathrm{t}}=$ resistance at $t^{\circ}$ centigrade.

$R_{0}=$ resistance at $0^{\circ}$ centigrade

$\Delta t=$ difference in temperature.

\section{Inductance in RLCG circuit $(L)$}

The inductance can be derived for a single phase two wire line. A single phase line consisting of two solid conductors of radii " $r_{1}$ " and " $r_{2}$ " are kept at a distance " $D$ ". The inductance in each conductor is due to internal and external flux linkages.

The inductance of first conductor due to external flux linkage is given by,

$$
L_{1}=2 \times 10^{-7} \ln \frac{D}{r_{1}} \mathrm{H} / \mathrm{m}
$$

The inductance of second conductor due to external flux linkage is given by

$$
L_{2}=2 \times 10^{-7} \ln \frac{D}{r_{2}} \mathrm{H} / \mathrm{m}
$$

The total inductance of the circuit is

$$
\begin{gathered}
L=L_{1}+L_{2} \mathrm{H} / \mathrm{m} \\
\text { i.e. } L=4 \times 10^{-7} \ln \frac{D}{r} \mathrm{H} / \mathrm{m}
\end{gathered}
$$

Or the above equation can be written as,

$$
L=0.921 \log \frac{D}{r} \mathrm{mH} / \mathrm{km}
$$

Thus the inductance is modelled in RLCG line using the above equation. 


\section{Capacitance in RLCG circuit $(C)$}

Considering the same two solid conductors, the capacitance value is calculated. The two conductors are named as " $c_{1}$ " and " $c_{2}$ ". The potential difference between the two conductors is given as $V_{c 1 c 2}$. The capacitance per unit length is generally given by,

$$
C_{c 1 c 2}=\frac{q}{V_{c 1 c 2}}
$$

$q$ is the charge on the conductor per meter.

$V_{c 1 c 2}$ is given by,

$$
V_{c 1 c 2}=\frac{q}{2 \Pi \varepsilon} \ln \frac{D^{2}}{r_{1} r_{2}}
$$

$\xi$ is the permittivity of the medium and $D$ is the distance and $r_{1}$ and $r_{2}$ are the radii of the conductors.

Substituting (21) in (20), the capacitance obtained is

$$
C_{c 1 c 2}=\frac{0.01206}{\log \frac{D}{r}} \mu \mathrm{F} / \mathrm{km}
$$

Thus the capacitance value is also obtained.

Using the design equations, the transmission line parameters are tabulated in Table 2.

\section{MNLC with Transmission Line}

\section{A. RLCG LINE with Negative DC Input Voltage}

In this section, initially a negative DC voltage $V_{i n}$ is fed as an input to the RLCG transmission line and its results are verified. Then the transmission line is interfaced with the proposed MNLC and the data pulse retrieval is effectively shown.

Figure 11 shows the transmission line fed with negative DC input signal. The DC input of $50 \mathrm{~V}$ is given to the RLCG line and the output voltage is measured. For an input of $-50 \mathrm{~V}$, the output of $-5.38 \mathrm{~V}$ is obtained from the transmission line which is shown in the Figure 12 and Figure 13.

Table 2. Parameters of RLCG line.

\begin{tabular}{ccc}
\hline Sl. No & Parameters & Value \\
1 & $\mathrm{R}$ & $0.83 \Omega / \mathrm{m}$ \\
2 & $\mathrm{~L}$ & $5.8 \mu \mathrm{H} / \mathrm{m}$ \\
3 & $\mathrm{C}$ & $0.485 \mathrm{nF} / \mathrm{m}$ \\
\hline
\end{tabular}

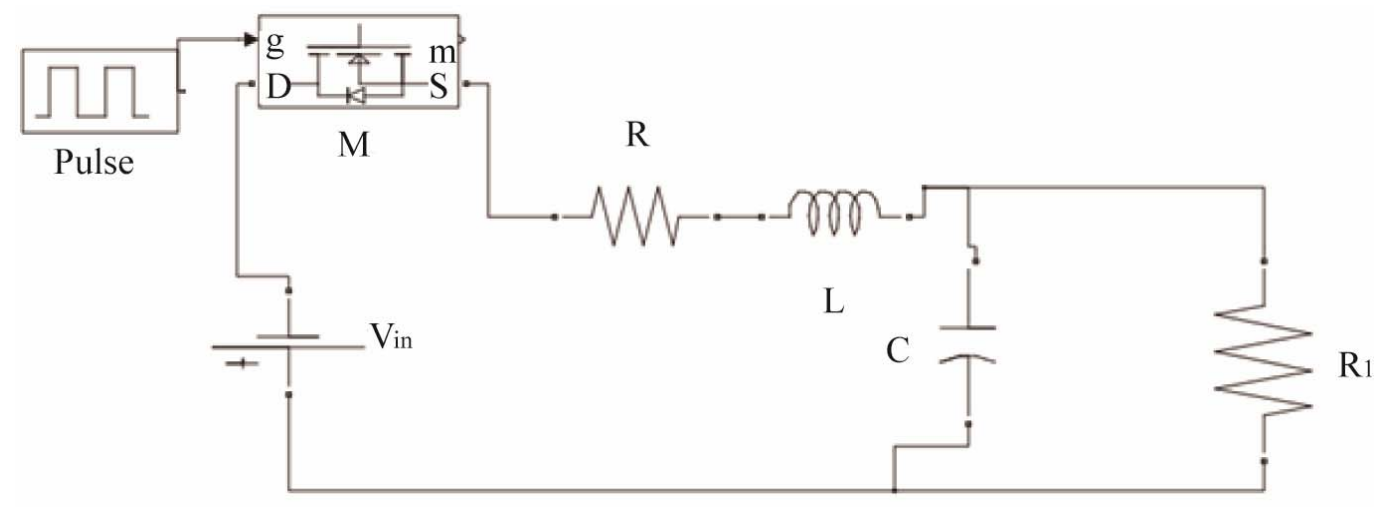

Figure 11. RLCG line fed with negative DC input. 


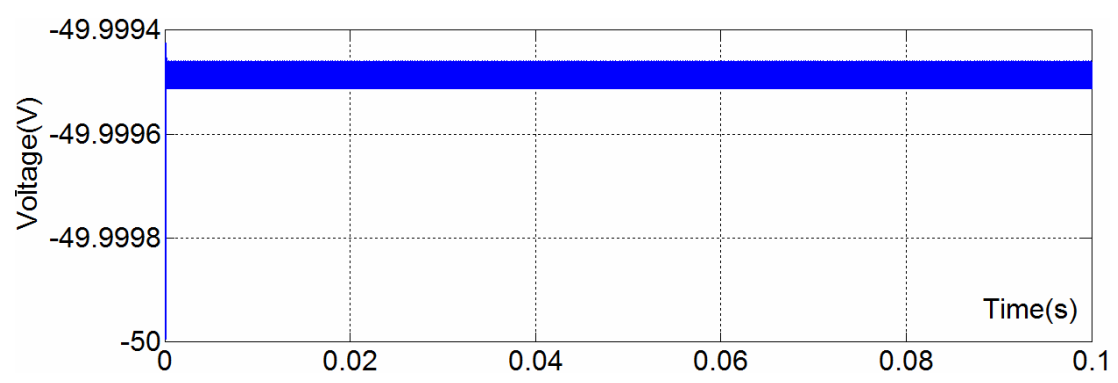

Figure 12. Negative DC input to RLCG line fed with negative DC input.

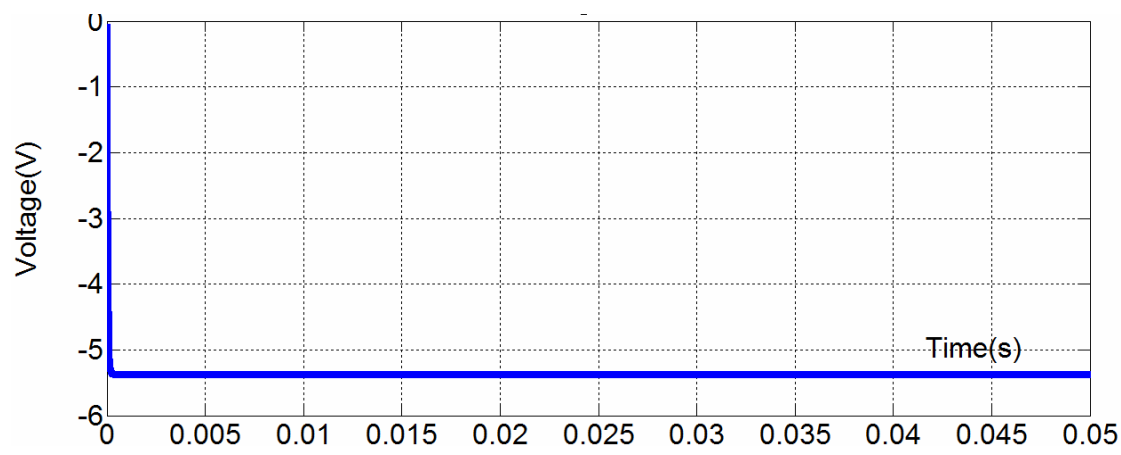

Figure 13. Output voltage of RLCG transmission line.

\section{B. Interface of MNLC with RLCG Transmission Line}

The interface of MNLC with transmission line is shown below in Figure 14. The data to be transmitted is given as $50 \mathrm{~Hz}$ signal of 50\% Duty ratio. It is anded with the required $25 \mathrm{KHz}$ switching frequency signal [6]. The anded pulse switches on and off the MNLC. Now the MNLC is switched on and off with the anded pulse of duty ratio $50 \%$ from which the data pulse is retrieved at the output of a transmission line. During on, MNLC is charged due to the availability of passive components $\mathrm{L}$ and $\mathrm{C}$. This charge should be discharged to the load which happens during off state of the switch. The entire energy is transferred to the load during this off state. The signal of $50 \mathrm{~Hz}$ which makes the charging and discharging of MNLC is retrieved at the terminating line of transmission. This circuit shows a retrieval of $50 \mathrm{~Hz}$ pulse at the output side of a transmission line. A series of data pulse stream transmission can also be achieved with this simple DC-DC circuit.

\section{B.1. Simulation Waveforms of MNLC Interface with RLCG Transmission Line}

The MNLC interface with RLCG transmission line is simulated using various switching frequencies like 25 $\mathrm{kHz}, 1 \mathrm{kHz}$ and $500 \mathrm{~Hz}$ whose outputs are shown below.

\section{a. With $25 \mathrm{kHz}$}

In this, the switching frequency of $25 \mathrm{kHz}$ is chosen for MNLC. The data to be transmitted is the same $50 \mathrm{~Hz}$ signal which is already portrayed in the previous section. Both the signals are anded and provided as a switching pulse to MNLC. The output voltage of MNLC is a very high boosted output with less ripple. This again is transmitted through the RLCG transmission line. The output obtained from the line is a low value output because of the losses introduced in the transmission line due to the passive components. This voltage is compared with a comparator signal and the pulse of $50 \mathrm{~Hz}$ is retrieved at the transmission line. Thus the following figures depict the simulated outputs. Figure 15 shows the anded $50 \mathrm{~Hz}$ with $25 \mathrm{kHz}$ pulse of MNLC. The magnitude of $50 \mathrm{~V}$ is given as an input voltage to MNLC as shown in Figure 16. The output voltage of MNLC is found to be $-325 \mathrm{~V}$ as shown in Figure 17 which is again fed as an input to the transmission line that acts as a load to the converter. The output voltage of transmission line is found to be $-37 \mathrm{~V}$ which is shown in the Figure 18 [7]. This is again compared with a comparator signal to retrieve the $50 \mathrm{~Hz}$ pulse at the output.

Thus the Figure 19(a) and Figure 19(b) shows the pulse to be transmitted and the pulse transmitted at the output [8]. Since the transmitted voltage reaches its steady state between the time duration $4.986 \mathrm{~s}$ and $4.99 \mathrm{~s}$, the pulse retrieval is shown with the same duration. Thus effective pulse transmission is achieved using this MNLC which highly prove to be economical in the form of circuit design. 
PULSE TO BE TRANSMITTED

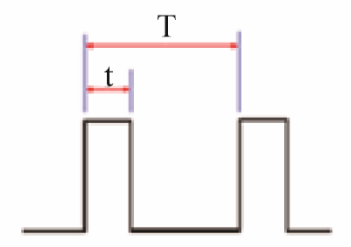

MNLC
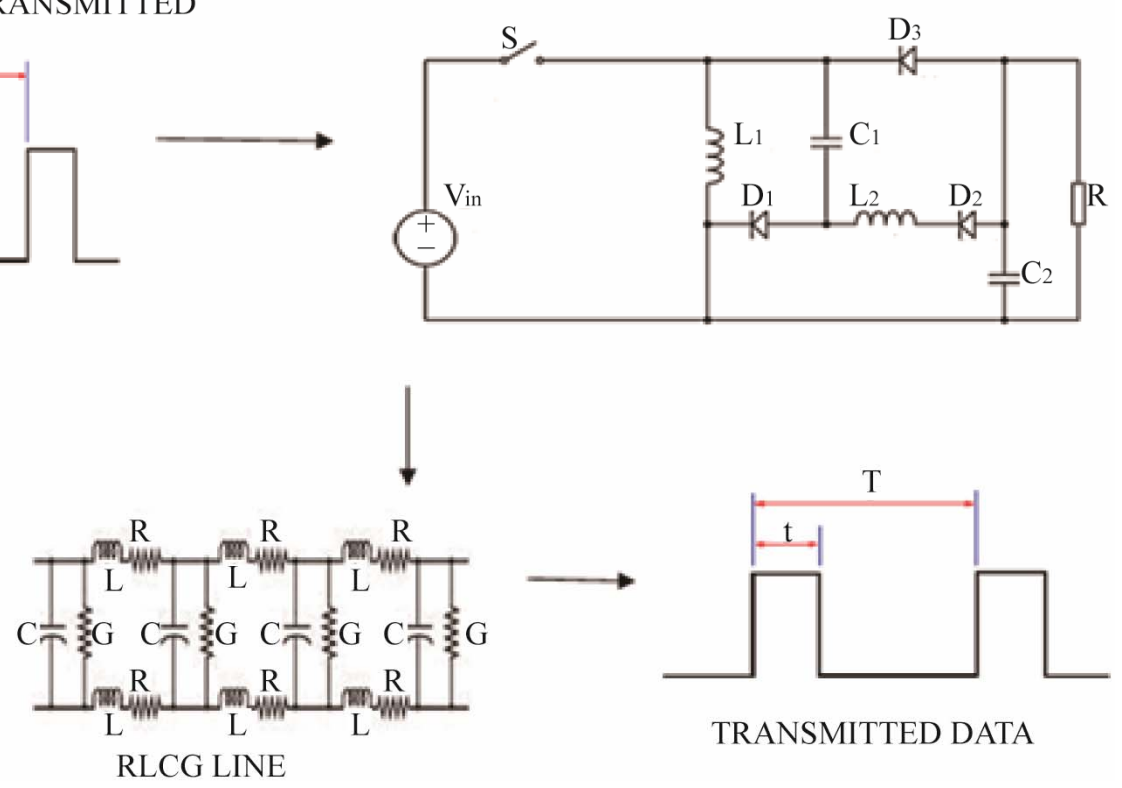

Figure 14. Interface of MNLC with RLCG transmission line.

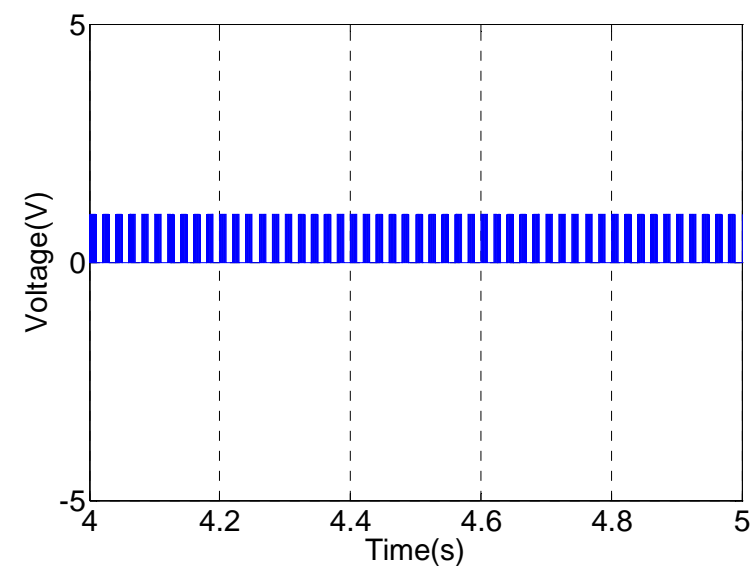

Figure 15. Input pulse given to MNLC-ANDED pulse.

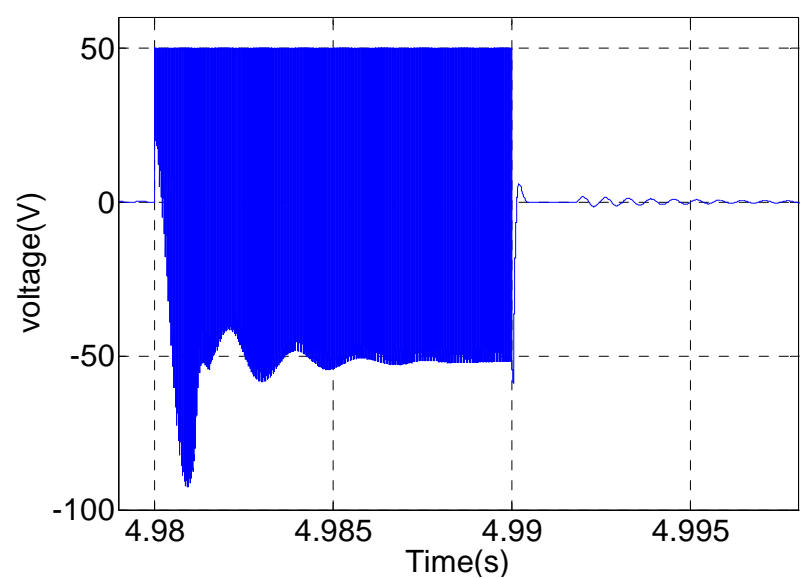

Figure 16. Input voltage of MNLC given as $50 \mathrm{~V}$. 


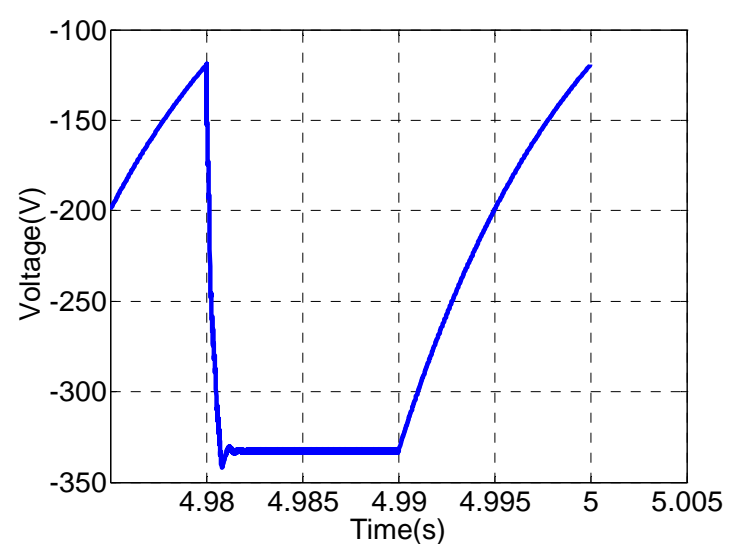

Figure 17. Output voltage of MNLC.

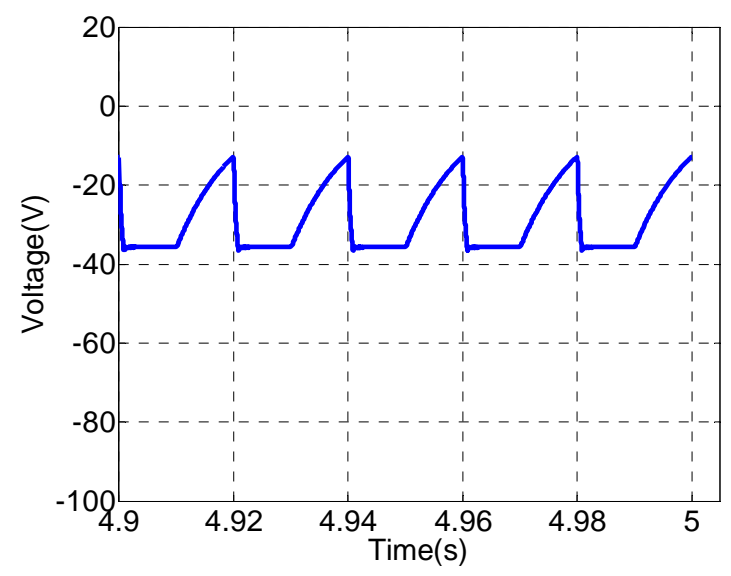

Figure 18. Output voltage of transmission line.

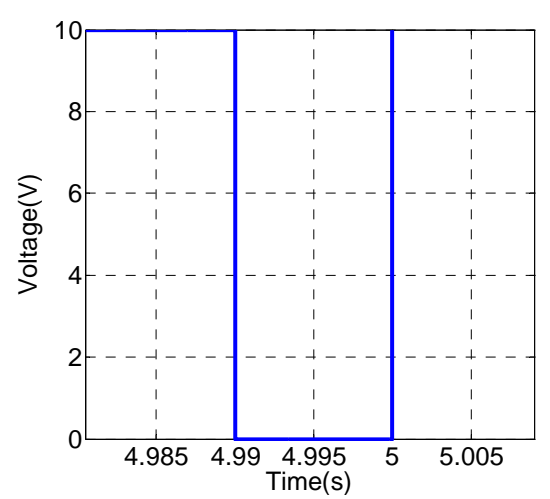

(a)

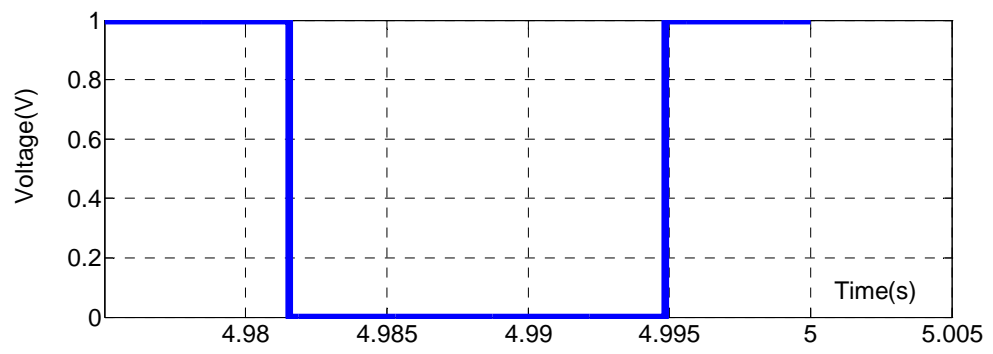

(b)

Figure 19. (a) Pulse data to be transmitted; (b) Transmitted data.

\section{b. With $1 \mathrm{KHz}$}

The pulse retrieval at the output of a RLC transmission line is shown here for a frequency of $1 \mathrm{KHz}$ [9]. The input pulse of $1 \mathrm{KHz}$ is given to MNLC which is shown in the Figure 20. The input voltage of $50 \mathrm{~V}$ is given as an input to MNLC as shown in the Figure 21. The output voltage of MNLC is $-850 \mathrm{~V}$ as shown in the Figure 22. Figure 23 shows the output voltage across the transmission whose value falls to $-110 \mathrm{~V}$ due to impedance losses in RLC line. The pulse retrieved at the output by comparing with a comparator signal is shown in the Figure 24(b) along with the transmitting pulse in Figure 24(a). 


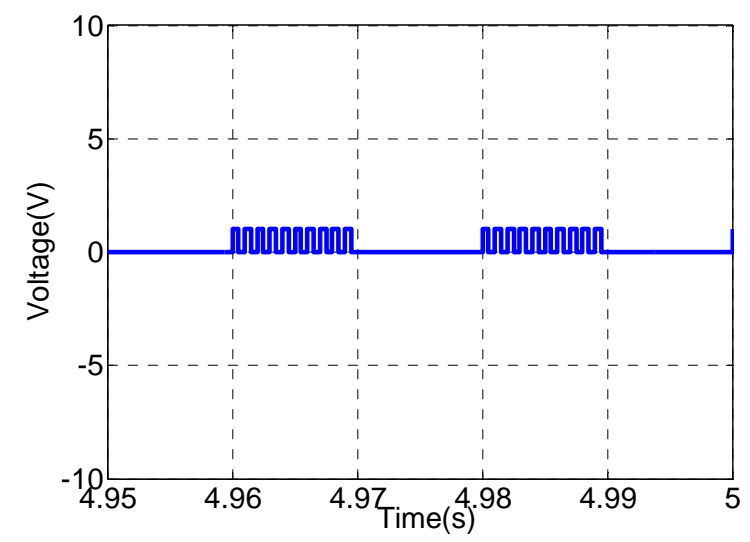

Figure 20. Input pulse of MNLC at $1 \mathrm{KHz}$.

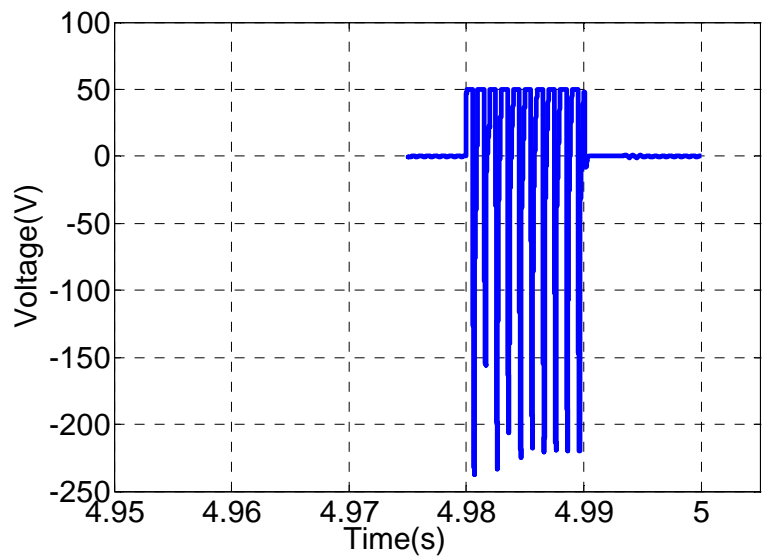

Figure 21. Input voltage of $50 \mathrm{~V}$ fed to MNLC at $1 \mathrm{KHz}$.

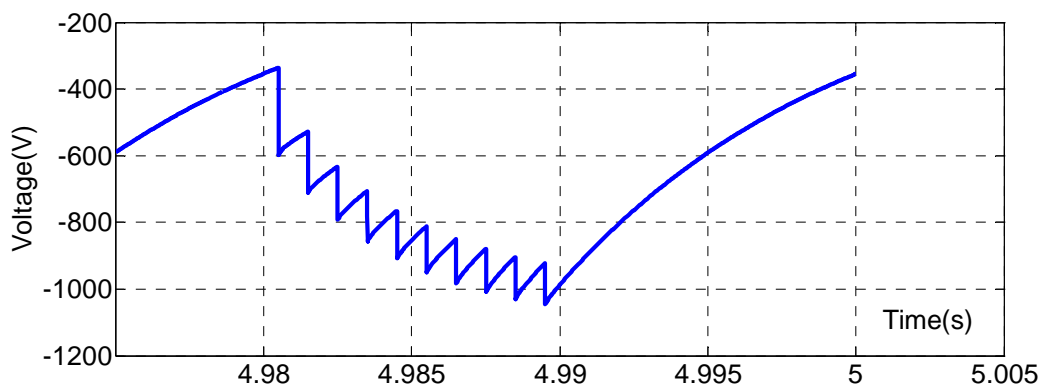

Figure 22. Output voltage of MNLC at $1 \mathrm{KHz}$.

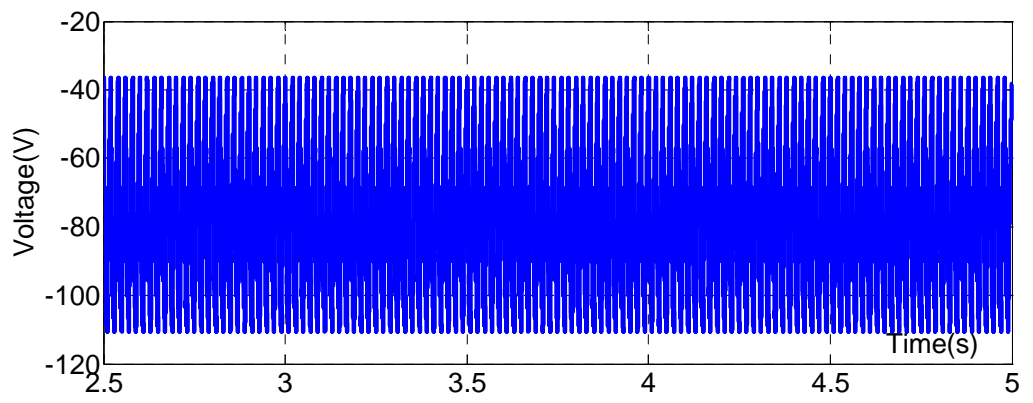

Figure 23. Output voltage of MNLC at $1 \mathrm{KHz}$. 


\section{With $500 \mathrm{~Hz}$}

The input voltage of MNLC is $50 \mathrm{~V}$ which is shown in the Figure 25. The output voltage of $-700 \mathrm{~V}$ is shown in the Figure 26. Figure 27 shows the output voltage of $-80 \mathrm{~V}$ across the transmission line [10] and Figure 28(a) and Figure 28(b) shows the pulse to be transmitted and the pulse retrieved at the output of transmission line.

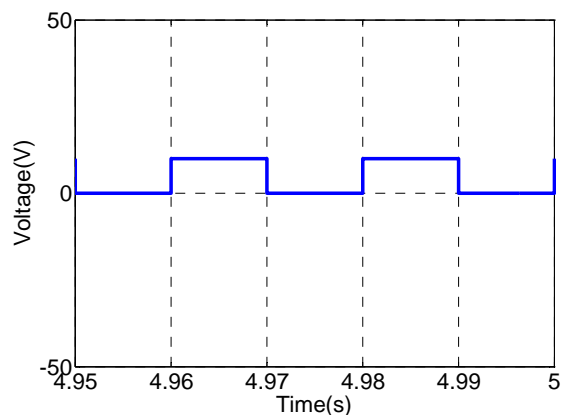

(a)

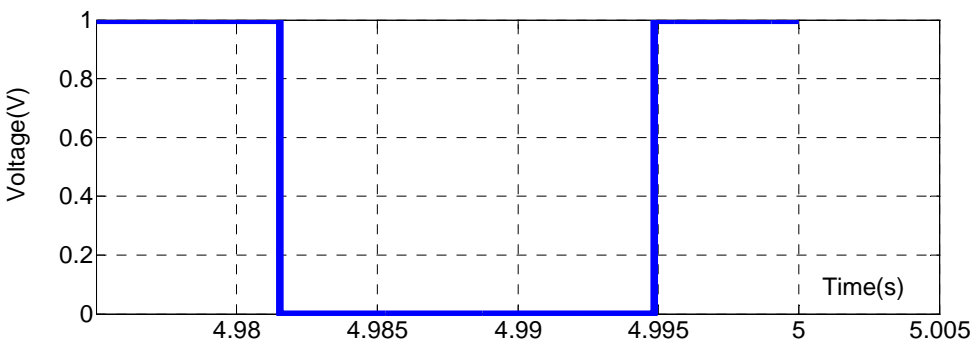

(b)

Figure 24. (a) Pulse data to be transmitted; (b) Transmitted data.

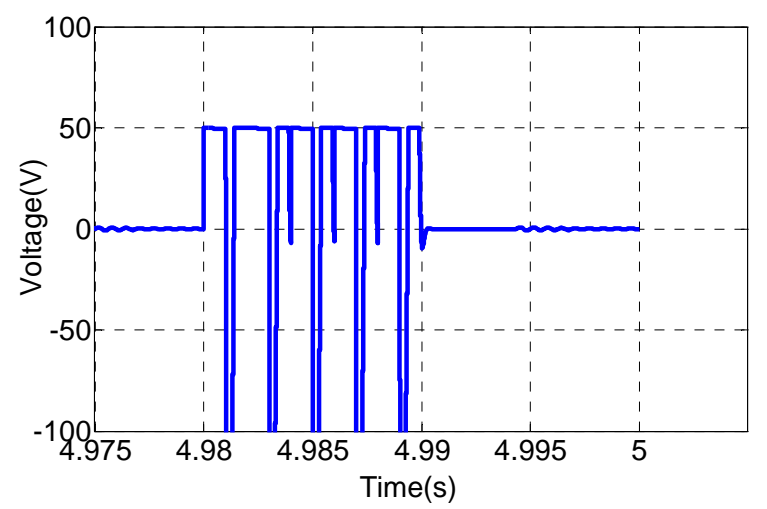

Figure 25. Input voltage of $50 \mathrm{~V}$ fed to MNLC.

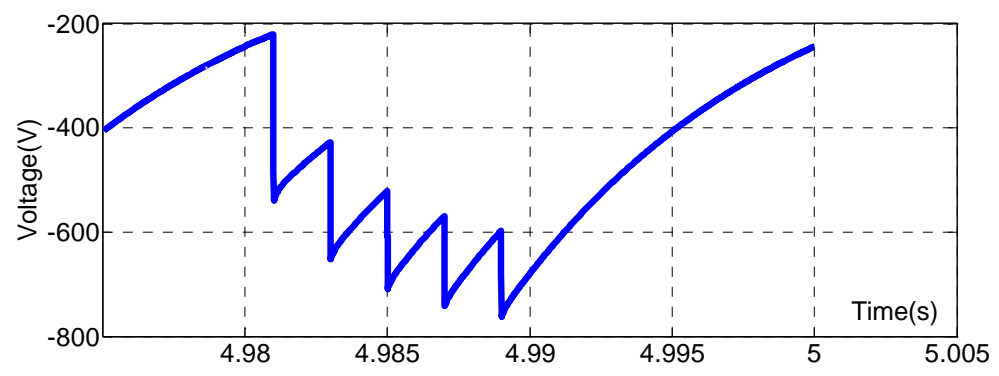

Figure 26. Output voltage of MNLC at $500 \mathrm{~Hz}$.

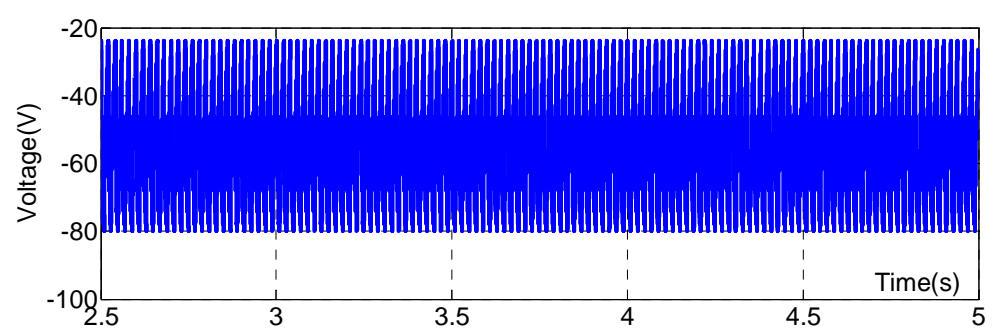

Figure 27. Output voltage of transmission line. 


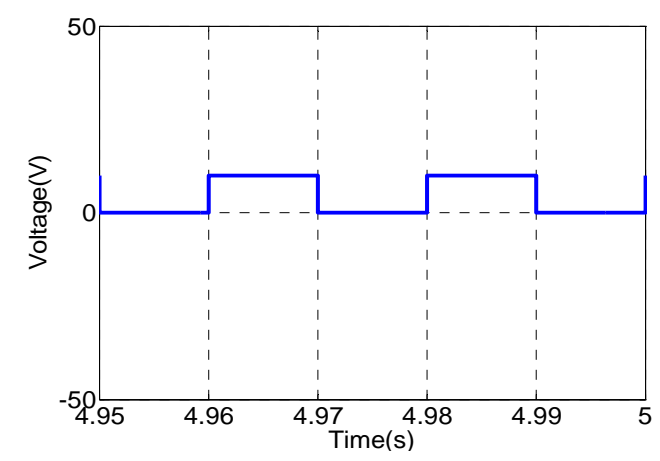

(a)

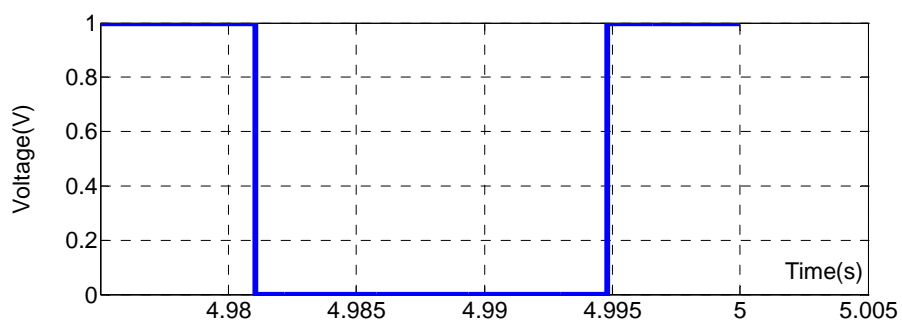

(b)

Figure 28. (a) Pulse data to be transmitted; (b) Transmitted output.
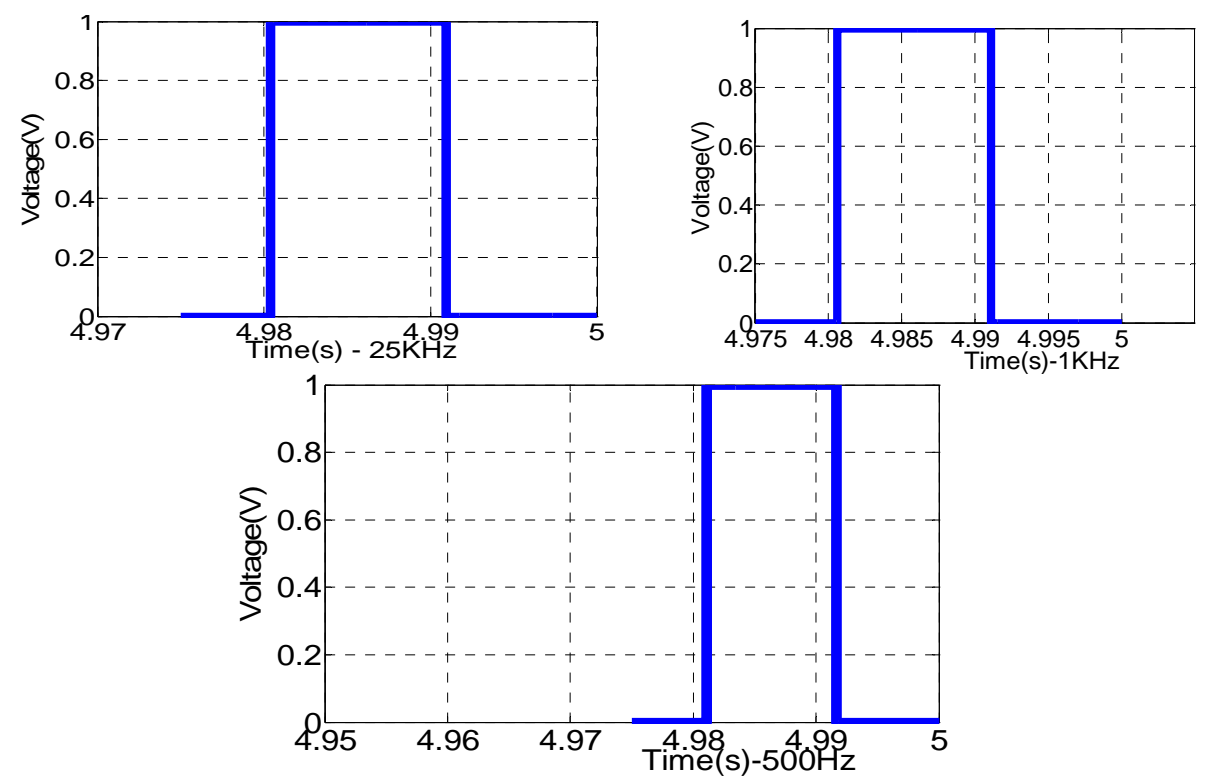

Figure 29. Comparative analysis of transmitted data pulse $-25 \mathrm{kHz}, 1 \mathrm{kHz}, 500 \mathrm{~Hz}$.

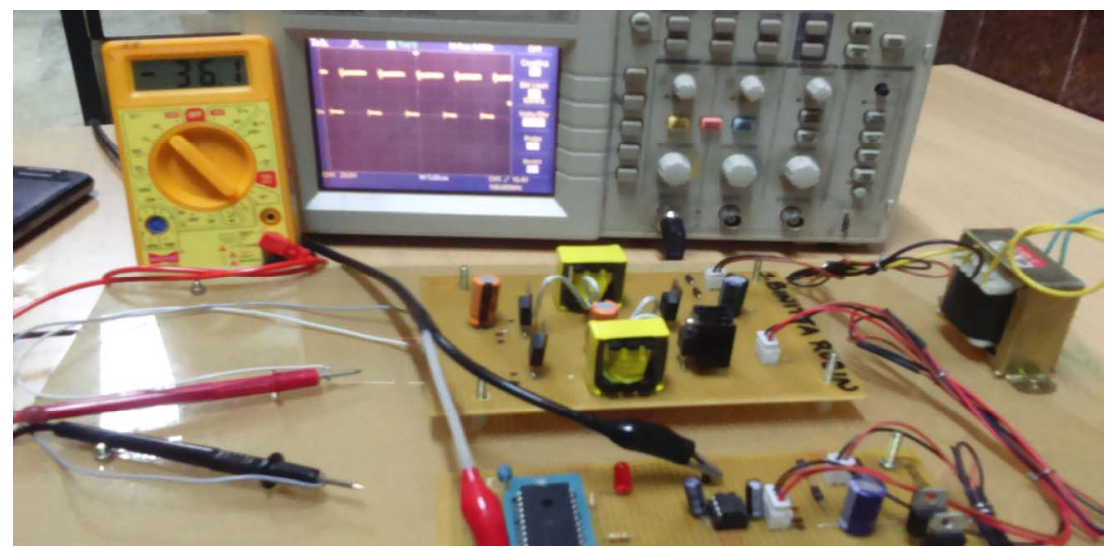

Figure 30. Hardware model of MNLC.

Figure 29 shows the data pulse is retrieved at the same period between $4.981 \mathrm{~s}$ and $4.991 \mathrm{~s}$ for all the three switching frequencies of $25 \mathrm{kHz}, 1 \mathrm{kHz}$ and $500 \mathrm{~Hz}$. Thus the stability of the output is shown between the duration $4.981 \mathrm{~s}$ and $4.991 \mathrm{~s}$ and the pulse duration is maintained for the same. 


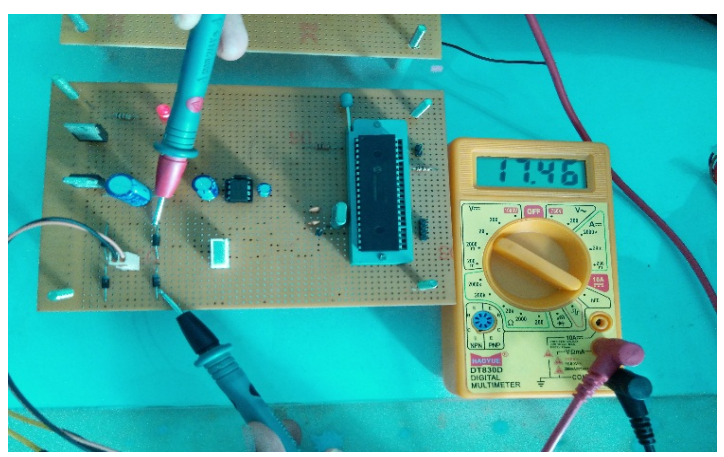

Figure 31. Bridge rectifier output of $17.46 \mathrm{~V}$.

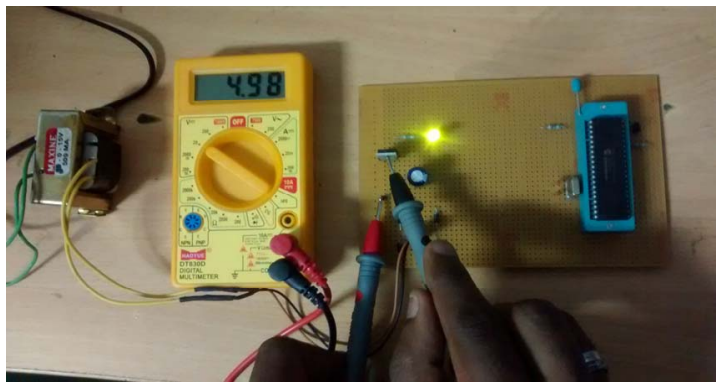

Figure 32. Regulator output of $5 \mathrm{~V}$.

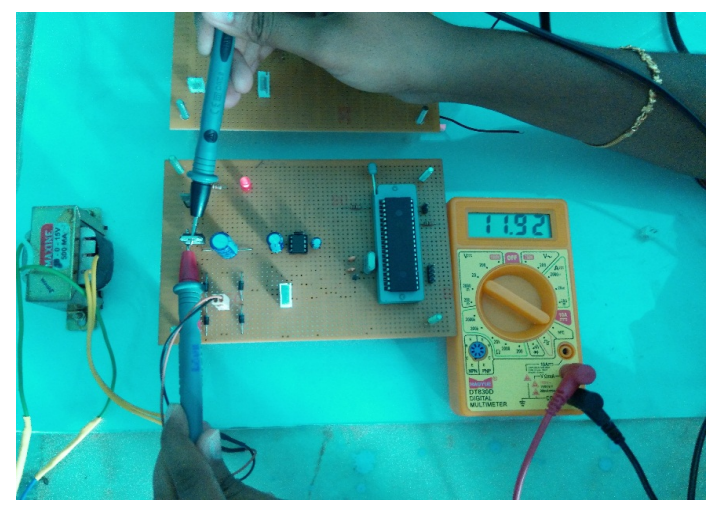

Figure 33. Regulator output of $12 \mathrm{~V}$.

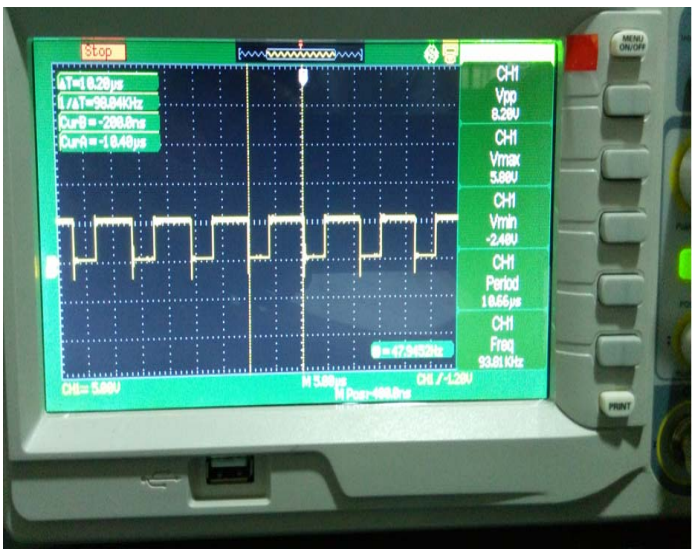

Figure 34. Switching pulse of $67 \%$ duty ratio. 


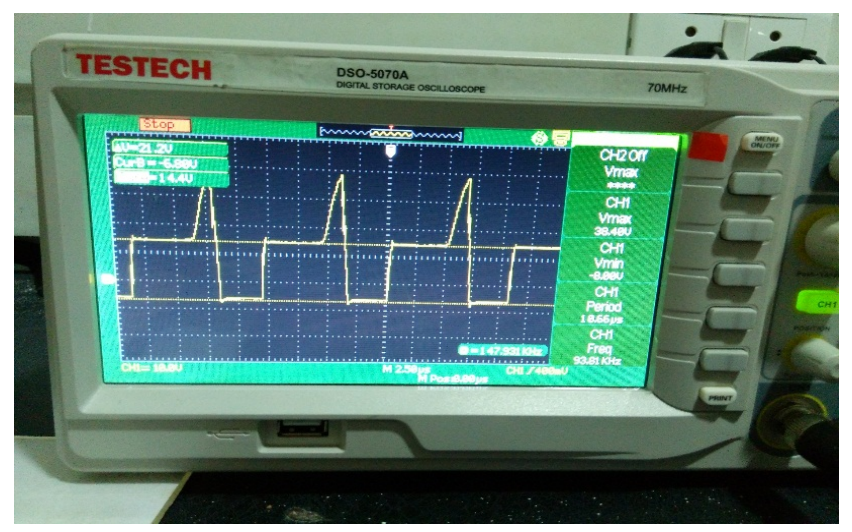

Figure 35. Pulse output from the driver.

\section{Hardware Implementation of MNLC}

This section portrays the prototype developed for MNLC and shows the boosted output voltage. This voltage is transmitted through the RLCG line and the respective output from the line is measured. It is again compared with a comparator signal for retrieving the data pulse transmitted. This is how the transmitted voltage aids in the retrieval of pulse. For an input of $6 \mathrm{~V}$, Figure 30 shows an output of $-36.1 \mathrm{~V}$ that depicts six times the input voltage produced. Thus a high gain converter with its simplified topology aids in data transmission.

Figure 31 depicts the bridge rectifier output of $17.46 \mathrm{~V}$ from which the regulated output of $5 \mathrm{~V}$ and $12 \mathrm{~V}$ is produced from the regulator IC 7805 and 7812 which is shown in Figure 32 and Figure 33. The generated pulse of $67 \%$ duty ratio from PIC microcontroller is shown in Figure 34 and the driver pulse to drive the MOSFET switch of the converter from IR2101 with increased amplitude is shown in Figure 35.

\section{Conclusion}

The pulse data transmission using RLCG impedance line with the aid of MNLC is effectively achieved here. The health hazards of RF are overcome in this paper by introducing a simple lift converter which effectively charges and discharges to the load thereby influencing the process of data transmission on a ground level. The pulse data retrieval at the output is obtained by comparing the output signal from MNLC with a reference signal. Thus any data pattern can be transmitted and received using this kind of simple and efficient method which becomes highly helpful in telecom sectors.

\section{References}

[1] Guo, Y.J. (2012) Antenna and RF Technologies for Future Wireless Communications Systems. 2012 IEEE Asia-Pacific Conference on Antennas and Propagation (APCAP), Singapore, 27-29 August 2012, 74-75. http://dx.doi.org/10.1109/APCAP.2012.6333154

[2] Adams, N., Bitman, J., Copeland, D., Srinivasan, D. and Garcia, A. (2013) RF Interference at Ground Stations Located in Populated Areas. 2013 IEEE Aerospace Conference, Big Sky, Montana, 2-9 March 2013, 1-8. http://dx.doi.org/10.1109/AERO.2013.6496880

[3] Yamaguchi, M., Tanaka, S., Endo, Y., Nagata, M., Matsui, H., Iwanami, M. and Tsukamoto, K. (2014) IC Chip Level Low Noise Technology for High Speed and High Quality Telecommunication Systems. 2014 Asia-Pacific Microwave Conference, Sendai, 4-7 November 2014, 540-542.

[4] Berkovich, Y., Axelrod, B., Madar, R. and Twina, A. (2015) Improved Luo Converter Modifications with Increasing Voltage Ratio. IET Power Electronics, 8, 202-212. http://dx.doi.org/10.1049/iet-pel.2014.0135

[5] Jiao, Y., Luo, F.L. and Zhu, M. (2011) Voltage-Lift Type Switched-Inductor Cells for Enhancing DC-DC Boost Ability: Principles and Integration in Luo Converter. IET Power Electronics, 4, 131-142. http://dx.doi.org/10.1049/iet-pel.2010.0021

[6] Guzmán, A., Mooney, J., Benmouyal, G., Fischer, N. and Kasztenny, B. (2010) Transmission Line Protection System for Increasing Power System Requirements. 2010 Proceedings of the International Symposium Modern Electric Power Systems (MEPS), Wroclaw, 20-22 September 2010, 1-11.

[7] Ezennaya, S., Udeze, C., Okafor, K., Onyedikachi, S. and Anierobi, C. (2013) Smart Grid Network Transmission Line 
RLC Modelling Using Random Power Line Synthesis Scheme. International Journal of Advanced Computer Science and Applications, 4, 298-306.

[8] Akhtar, A., Bakhshi, B., Harvey, G., et al. (2013) Data Transmission and Electrical Powering Flexibility for Cabled Ocean Observatories. 2013 OCEANS, San Diego, 23-27 September 2013, 1-7.

[9] Cullen, B. (2000) Convergence of Voice and Data Telecommunications Transmissions. Twenty-Second International Telecommunications Energy Conference, 2000, 12-16. http://dx.doi.org/10.1109/intlec.2000.884219

[10] Dhaene, T. and De Zutter, D. (1992) Selection of Lumped Element Models for Coupled Lossy Transmission Lines. IEEE Transactions on Computer Aided Design, 11, 805-815. http://dx.doi.org/10.1109/43.144845

\section{Submit or recommend next manuscript to SCIRP and we will provide best service for you:}

Accepting pre-submission inquiries through Email, Facebook, LinkedIn, Twitter, etc.

A wide selection of journals (inclusive of 9 subjects, more than 200 journals)

Providing 24-hour high-quality service

User-friendly online submission system

Fair and swift peer-review system

Efficient typesetting and proofreading procedure

Display of the result of downloads and visits, as well as the number of cited articles

Maximum dissemination of your research work

Submit your manuscript at: http://papersubmission.scirp.org/ 